\title{
Classic Bartter syndrome complicated with profound growth hormone deficiency: a case report
}

\author{
Masanori Adachi ${ }^{1 *}$, Toshihiro Tajima², Koji Muroya ${ }^{1}$ and Yumi Asakura ${ }^{1}$
}

\begin{abstract}
Introduction: Classic Bartter syndrome is a salt-wasting tubulopathy caused by mutations in the CLCNKB (chloride channel $\mathrm{Kb}$ ) gene. Although growth hormone deficiency has been suggested as a cause for persistent growth failure in patients with classic Bartter syndrome, in our opinion the diagnoses of growth hormone deficiency has been unconvincing in some reports. Moreover, Gitelman syndrome seems to have been confused with Bartter syndrome in some cases in the literature. In the present work, we describe a new case with CLCNKB gene mutations and review the reported cases of classic Bartter syndrome associated with growth hormone deficiency.
\end{abstract}

Case presentation: Our patient was a Japanese boy diagnosed as having classic Bartter syndrome at eight months of age. The diagnosis of Bartter syndrome was confirmed by CLCNKB gene analysis, which revealed compound heterozygous mutations with deletion of exons 1 to 3 (derived from his mother) and $\Delta \mathrm{L} 130$ (derived from his father). His medical therapy consisted of potassium (K), sodium chloride, spironolactone, and anti-inflammatory agents; this regime was started at eight months of age. Our patient was very short $(131.1 \mathrm{~cm},-4.9$ standard deviation) at 14.3 years and showed profoundly impaired growth hormone responses to pharmacological stimulants: $0.15 \mu \mathrm{g} / \mathrm{L}$ to insulin-induced hypoglycemia and $0.39 \mu \mathrm{g} / \mathrm{L}$ to arginine. His growth response to growth hormone therapy was excellent.

Conclusions: The present case strengthens the association between classic Bartter syndrome and growth hormone deficiency. We propose that growth hormone status should be considered while treating children with classic Bartter syndrome.

Keywords: Bartter syndrome, Salt-losing tubulopathy, Hypokalemia, Gitelman syndrome, Growth failure

\section{Introduction}

Classic Bartter syndrome (BS), also referred to as type III Bartter syndrome, is a rare genetic disorder characterized by salt wasting from the renal tubules, mainly the thick ascending loop of Henle [1]. It is caused by mutations in the CLCNKB gene that encodes the type $\mathrm{b}$ kidney chloride channel $(\mathrm{ClC}-\mathrm{Kb})$. Patients with classic BS fail to thrive from infancy and exhibit hypokalemia, metabolic alkalosis, hyperactive renin-aldosterone system, and overproduction of prostaglandins. Although potassium supplements, anti-aldosterone agents, and/or indomethacin are the mainstay of

\footnotetext{
* Correspondence: madachi@mars.sannet.ne.jp

'Department of Endocrinology and Metabolism, Kanagawa Children's

Medical Center, Mutsukawa 2-138-4 Minami-ku, Yokohama 232-8555, Japan

Full list of author information is available at the end of the article
}

therapy, management of growth failure and hypokalemia is still challenging $[1,2]$.

The association of growth hormone deficiency (GHD) with classic BS has been anecdotally reported, and GHD may be one of the causes of persistent growth failure frequently observed in patients with classic BS [2-8]. However, the degrees of GHD in the reported cases have been diverse, and hence, GHD has not yet been regarded as a definite complication of BS. In addition, most of the reported cases of BS accompanying GHD were not investigated on a molecular basis $[3,7,8]$. Moreover, Gitelman syndrome (GS) seems to have been confused with BS in older reports in the literature [4-6]. Here, we report a case of classic BS with documented CLCNKB gene mutations in a boy who was found to have profound 
GHD. We also present a literature review on the association between classic BS and GHD.

\section{Case presentation}

Our patient was a Japanese boy born at 41 weeks of gestation via spontaneous cephalic delivery, with a birth weight of $3,680 \mathrm{~g}$. His family history was remarkable in that his elder sister, who was five years older than him, had been diagnosed as having classic BS when she was five months old: her final height was $147.0 \mathrm{~cm}(-2.1$ standard deviation [SD]) and at a recent assessment her insulin-like growth factor 1 (IGF-1) level was $286 \mathrm{ng} / \mathrm{mL}$ (normal range for her age, 168 to $459 \mathrm{ng} / \mathrm{mL}$ ).

At eight months of age, our patient was diagnosed as having classic BS based on the following findings: failure to thrive, metabolic alkalosis $\left(\mathrm{pH} 7.423 ; \mathrm{HCO}_{3}{ }^{-}\right.$, $33.6 \mathrm{mmol} / \mathrm{L}$; base excess, +8.2$)$, hypokalemia $(2.9 \mathrm{mEq} / \mathrm{L})$, and hyperactive renin-aldosterone system (plasma renin activity (PRA), $270 \mathrm{ng} / \mathrm{mL} / \mathrm{h}$; normal value for his age, $2.58 \pm 1.41 \mathrm{ng} / \mathrm{mL} / \mathrm{h}$ ); aldosterone level, $850 \mathrm{pg} / \mathrm{mL}$ $(2,358 \mathrm{pmol} / \mathrm{L}$; normal value for his age, $173.7 \pm 96.3 \mathrm{pg} / \mathrm{mL})$. The diagnosis of BS was confirmed by CLCNKB gene analysis, which revealed compound heterozygous mutations with deletion of exons 1 to 3 (derived from his mother)

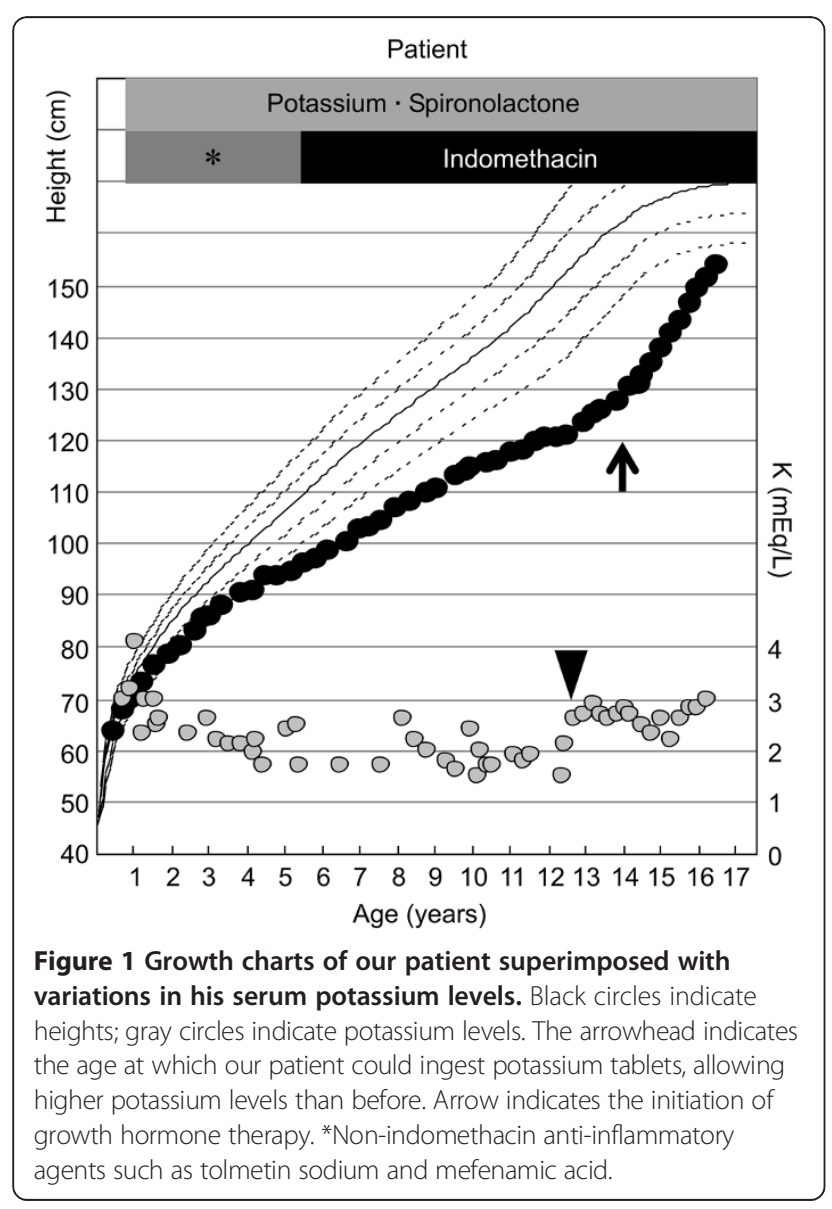

Table 1 Results of pharmacological growth hormone stimulation tests in our patient at 14 years of age

$\begin{array}{ccccc}0 & 30 & 60 & 90 & 120 \\ \text { minutes } & \text { minutes } & \text { minutes } & \text { minutes } & \text { minutes }\end{array}$

Insulin-induced

hypoglycemia:

\begin{tabular}{lccccc}
$\begin{array}{l}\text { Blood glucose } \\
\text { (mg/dL) }\end{array}$ & 94 & 54 & 93 & 99 & 92 \\
$\begin{array}{l}\text { Growth hormone } \\
\text { ( } \mu \text { g/L) }\end{array}$ & 0.11 & 0.07 & 0.15 & 0.13 & 0.08 \\
$\begin{array}{l}\text { Arginine: } \\
\begin{array}{l}\text { Growth hormone } \\
(\mu g / L)\end{array}\end{array}$ & 0.11 & 0.26 & 0.39 & 0.28 & 0.17 \\
\hline
\end{tabular}

and $\Delta \mathrm{L} 130$ (derived from his father), the latter of which has been reported previously by the authors TT and MA. Medical therapy consisting of potassium (K), sodium chloride, spironolactone, and anti-inflammatory agents was initiated at eight months of age and is still ongoing. However, as depicted in Figure 1, his serum $\mathrm{K}$ level remained considerably low because he was unable to consume large amounts of drugs, especially potassium preparations. Our patient also displayed mild intellectual impairment: he could only speak meaningful words by the age of three, and required specialized primary education.

When he was 11 years old, an investigation for macrohematuria led to the detection of renal stones with nephrocalcinosis. This complication resolved following the amelioration of hypokalemia, which was achieved by our patient's increased efforts to ingest potassium tablets.

At 14.3 years of age, his severe short stature $(131.1 \mathrm{~cm},-4.9 \mathrm{SD})$ prompted us to evaluate his growth

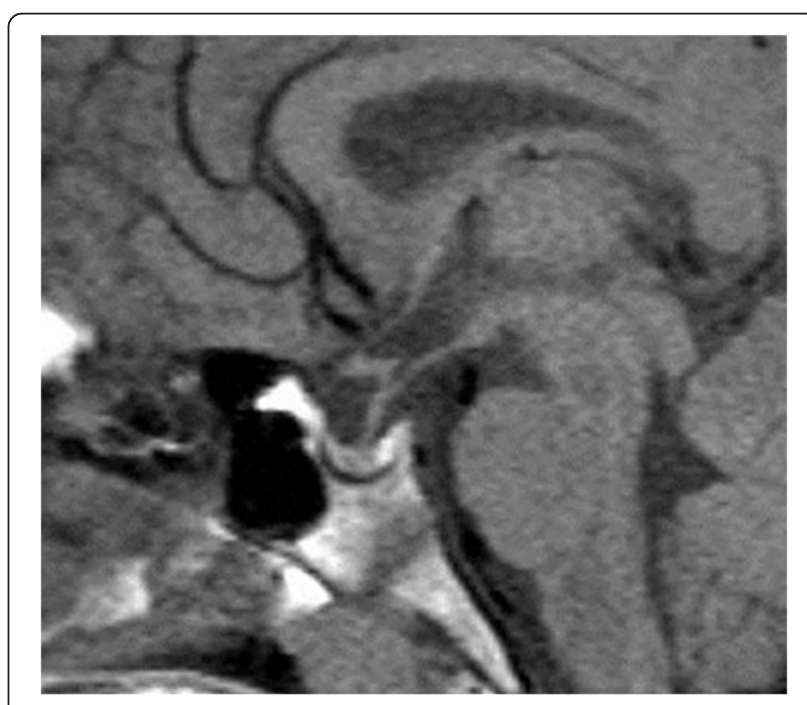

Figure 2 Magnetic resonance imaging scan of the pituitary gland of our patient. 
Table 2 Classical Bartter syndrome with growth hormone deficiency: cases from the literature

\begin{tabular}{|c|c|c|c|c|c|}
\hline Reference & Age, years & Sex & Mutation & GH peak $(\mu \mathrm{g} / \mathrm{L})$ to stimulants & IGF-1 (ng/mL) \\
\hline [9] & 5 & M & IVS2-1G > C/W610X & 9.3 (GLC), 8.0 (CLN), 8.2 (L-DOPA), 38.0 (ARG) & Not determined \\
\hline [10] & 8 & $\mathrm{~F}$ & Not determined & 2.9 (INS), 2.0 (CLN), 6.9 (GRF) & 122.1 \\
\hline [7] & 10 & M & Not determined & 3.20 (INS), 3.20 (L-DOPA) & 25 \\
\hline \multirow[t]{3}{*}{ [8] } & 10 & $\mathrm{~F}$ & Not determined & 0.70 (L-DOPA), 1.96 (CLN) & 41.5 \\
\hline & 11 & M & Not determined & 4.70 (L-DOPA), 1.79 (CLN) & 39.7 \\
\hline & 11 & M & Not determined & 0.50 (L-DOPA), 4.49 (CLN) & 38.3 \\
\hline \multirow[t]{2}{*}{ [2] } & 11 & M & 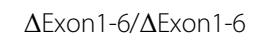 & 7.6 (ARG) & Low \\
\hline & 14 & M & 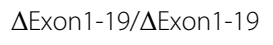 & 2.4 (ARG), 8.4 (GRF) & Low \\
\hline [3] & 22 & $\mathrm{~F}$ & Not determined & Absence (INS), 8.0 (ARG) & Not determined \\
\hline Present case & 14 & M & $\Delta \mathrm{L} 130 / \Delta$ Exon $1-3$ & 0.15 (INS), 0.39 (ARG) & 80 \\
\hline
\end{tabular}

ARG arginine, CLN clonidine, L-DOPA L-3,4-dihydroxyphenylalanine, GH growth hormone, GLC glucagon, GRF, growth hormone releasing factor, IGF-1 insulin-like growth factor 1 , INS insulin.

hormone $(\mathrm{GH})$ status, and he was found to have profound GHD. His serum levels of IGF-1 and IGF binding protein 3 were $80 \mathrm{ng} / \mathrm{mL}$ (normal range for his age, 178 to $686 \mathrm{ng} / \mathrm{mL}$ ) and $1.92 \mu \mathrm{g} / \mathrm{mL}$ (normal range for his age, 2.69 to $4.16 \mu \mathrm{g} / \mathrm{mL}$ ), respectively. Pharmacologically stimulated GH levels were 0.15 and $0.39 \mu \mathrm{g} / \mathrm{L}$ after insulin-induced hypoglycemia and arginine administration, respectively (Table 1 ). His bone age was 11.4 years (Tanner-Whitehouse 2-radius, ulna and short bones (TW2-RUS) method for Japanese individuals). Magnetic resonance imaging study results revealed no abnormalities in the hypothalamic-pituitary region (Figure 2).

GH therapy was initiated at 14.5 years of age at a dose of 21 to $27 \mu \mathrm{g} / \mathrm{kg} /$ day, which restored his growth remarkably (Figure 1). Although his pubertal stage progressed from Tanner stage 1 to stage 2 over the next two years, his bone maturation ( $\Delta$ bone age/ $\Delta$ chronological age) was 1.02. No significant change was observed in his serum potassium level during $\mathrm{GH}$ therapy.

\section{Discussion}

To the best of our knowledge, the association of BS with GHD was first reported in 1977 [3]. Thereafter, a number of similar reports have been published [2-8]. However, we believe that some of the older cases reported in the literature do not comply with the current definition and concept of BS and thus should be recognized as GS [4-6]. GS is another salt-losing tubulopathy caused by mutations in the $S L C 12 A 3$ gene that encodes the thiazide-sensitive sodium-chloride cotransporter (NCCT) [1]. Because classic BS and GS shared the laboratory finding of hypokalemic alkalosis, these conditions were not strictly discriminated until the era of molecular diagnosis.

Table 3 Gitelman syndrome (including definite or probable cases) and GHD: cases from the literature

\begin{tabular}{|c|c|c|c|c|c|}
\hline Reference & Age, years & Sex & Mutation & GH peak $(\mu \mathrm{g} / \mathrm{L})$ to stimulants & IGF-1 \\
\hline \multirow[t]{2}{*}[12]{} & 3 & $M$ & 2614fr/unknown (SLC12A3) & $<8$ (INS), <8 (ARG), <8 (CLN) & Not determined \\
\hline & 9 & F & G186D/unknown (SLC12A3) & $6(\mathrm{CLN})$ & $89 \mathrm{ng} / \mathrm{mL}$ \\
\hline \multirow[t]{3}{*}{ [5] } & 3 & M & Not determined & 3.3 (L-DOPA), 7.3 (CLN) & $0.26 \mathrm{U} / \mathrm{mL}$ \\
\hline & 9 & F & Not determined & 9.2 (L-DOPA), 4.8 (CLN) & $0.67 \mathrm{U} / \mathrm{mL}$ \\
\hline & 19 & $\mathrm{~F}$ & Not determined & $6.0(\mathrm{CLN})$ & Not determined \\
\hline [6] & 7 & M & Not determined & 9.8 (INS + ARG) & Not determined \\
\hline [11] & 9 & M & Not determined & 2.1 (INS), 3.2 (CLN), 1.8 (L-DOPA) & $55 \mathrm{ng} / \mathrm{mL}$ \\
\hline [13] & 10 & F & Not determined & 7.5 (L-DOPA), 6.9 (CLN) & Normal \\
\hline [14] & 11 & M & Not determined & 10.8 (GRF), 7.0 (CLN) & $0.43 \mathrm{U} / \mathrm{mL}$ \\
\hline [15] & 11 & M & Not determined & 5 (INS), 1 (CLN), 13 (GRF) & $292 \mathrm{ng} / \mathrm{mL}$ \\
\hline [4] & 11 & M & Not determined & $11(\mathrm{CLN}), 3.1(\mathrm{GLC})$ & $0.74 \mathrm{U} / \mathrm{mL}$ \\
\hline$[16]$ & 13 & M & Not determined & 5.4 (INS), 5.4 (ARG), 12 (GLC-PPL) & $0.19 \mathrm{U} / \mathrm{mL}$ \\
\hline
\end{tabular}

Cases were categorized as Gitelman syndrome according to the authors' own judgment, even if they were described as Bartter syndrome in the original reports. ARG arginine, CLN clonidine, L-DOPA L-3,4-dihydroxyphenylalanine, GH growth hormone, GLC glucagon, GRF growth hormone releasing factor, IGF-1 insulin-like growth factor 1, INS insulin, PPL propranolol. 
Molecular diagnosis is a prerequisite for the detailed study of classic BS.

Tables 2 and 3 summarize cases of GHD reported to date classified as BS [2,3,7-10] and GS [4-6,11-16], respectively. Our patient's case is remarkable in that the diagnosis of classic BS was established molecularly. In addition, our patient's GH responses to pharmacological stimulants were most profoundly impaired among the hitherto reported cases. Although one may argue that hypokalemia may blunt the $\mathrm{GH}$ response and lead to false negative results, the excellent response to $\mathrm{GH}$ therapy made us suspicious for the presence of GHD. By adding our patient to the existing list of cases of GHD concomitant with BS, we believe that GHD should be regarded as a complication in classic BS.

Flyvbjerg et al. suggested that hypokalemia is a causative factor of GHD [17]. These authors stated that mice fed a low potassium diet showed growth retardation with low IGF-1 levels and attenuated GH response to GH-releasing factor (GRF). From this observation, hypokalemia seems to be one of the possible factors responsible for GHD in classic BS. This hypothesis is strengthened by the findings that GHD has also been reported in other diseases predisposing to hypokalemia, such as GS (Table 3) and the Bartter-like Dent disease [18]. In addition, this hypothesis can help to differentiate GHD (our patient in the present report) from non-GHD (his sister). Because large amounts of potassium could be administered via the gastric tube or tablets, a higher serum potassium level could be maintained in the sister, which may have prevented the development of GHD. Furthermore, the lack of association between GHD and antenatal BS, which is caused by mutations in either the SLC12A1 (type I BS) or KCNJ1 (type II BS) gene, can be explained by the observation that the correction of hypokalemia is generally easier in antenatal BS than in classic BS.

However, factors other than hypokalemia may be necessary for developing GHD. Patients with familial aldosteronism, rare genetic forms of primary aldosteronism, present with hypokalemia and some of them are refractory to medical therapy, yielding to long standing hypokalemia [19]. Regardless, GHD has not been reported to date in patients with familial aldosteronism. Thus, an aim of our future studies would be to determine the precise mechanism by which GHD develops in patients with classic BS.

\section{Conclusions}

In summary, we report our experience of profound GHD in a boy with mutations in the CLCNKB gene, and propose that $\mathrm{GH}$ status should be monitored while treating salt-losing tubulopathies including classic BS and GS.

\section{Consent}

Written informed consent was obtained from the patient's next-of-kin for publication of this case report and any accompanying images. A copy of the written consent is available for review by the Editor-in-Chief of this journal.

This study was approved by the Institutional Review Board of Kanagawa Children's Medical Center and followed the World Medical Association Declaration of Helsinki regarding ethical conduct of research involving human subjects.

\begin{abstract}
Abbreviations
BS: Bartter syndrome; GH: Growth hormone; GHD: GH deficiency; GRF: GH-releasing factor; GS: Gitelman syndrome; IGF-1: Insulin-like growth factor 1 .
\end{abstract}

\section{Competing interests}

The authors declare that they have no competing interests.

\section{Authors' contributions}

MA treated our patient from the beginning, performed the CLCNKB gene analysis and evaluated the GH status of our patient. MA also wrote the manuscript. TT and KM planned and performed the CLCNKB gene analysis. YA and KM critically reviewed and revised the manuscript. All authors read and approved the final manuscript.

\section{Acknowledgements}

We thank Ms Reiko Iwano, Department of Endocrinology and Metabolism, Kanagawa Children's Medical Center, Japan, for her excellent technical assistance.

\section{Author details}

${ }^{1}$ Department of Endocrinology and Metabolism, Kanagawa Children's Medical Center, Mutsukawa 2-138-4 Minami-ku, Yokohama 232-8555, Japan. ${ }^{2}$ Department of Pediatrics, Hokkaido University School of Medicine, Sapporo 060-8635, Japan.

Received: 12 August 2013 Accepted: 28 October 2013

Published: 30 December 2013

\section{References}

1. Seyberth HW, Schlingmann KP: Bartter- and Gitelman-like syndromes: salt-losing tubulopathies with loop or DCT defects. Pediatr Nephrol 2011, 26:1789-1802

2. Bettinelli $A$, Borsa N, Bellantuono R, Syrèn ML, Calabrese R, Edefonti A, Komninos J, Santostefano M, Beccaria L, Pela I, Bianchetti MG, Tedeschi S: Patients with biallelic mutations in the chloride channel gene CLCNKB: long-term management and outcome. Am J Kidney Dis 2007, 49:91-98.

3. Lefebvre J, Racadot A, Dequiedt P, Linquette M: Électrolytes échangeables, glycorégulateur et hormone de croissance au cours d'un syndrome de Bartter [in French]. Ann Endocrinol (Paris) 1977, 38:385-386.

4. Requeira O, Rao J, Baliga R: Response to growth hormone in a child with Bartter's syndrome. Pediatr Nephrol 1991, 5:671-672.

5. Ruvalcaba RH, Martinez FE: Case report: familial growth hormone deficiency associated with Bartter's syndrome. Am J Med Sci 1992, 303:411-414.

6. Boer LA, Zoppi G: Bartter's syndrome with impairment of growth hormone secretion. Lancet 1992, 340:860.

7. Akil I, Ozen S, Kandiloglu AR, Ersoy B: A patient with Bartter syndrome accompanying severe growth hormone deficiency and focal segmental glomerulosclerosis. Clin Exp Nephrol 2010, 14:278-282.

8. Buyukcelik M, Keskin M, Kilic BD, Kor Y, Balat A: Bartter syndrome and growth hormone deficiency: three cases. Pediatr Nephrol 2012, 27:2145-2148.

9. Fukuyama S, Hiramatsu M, Akagi M, Higa M, Ohta T: Novel mutations of the chloride channel Kb gene in two Japanese patients clinically 
diagnosed as Bartter syndrome with hypocalciuria. J Clin Endocrinol Metab 2004, 89:5847-5850.

10. Nariai A, Yokoya S, Kato K: A case of Bartter's syndrome with growth hormone deficiency [abstract]. Clin Pediatr Endocrinol 1993, 2:165.

11. Ko CW, Koo JH: Recombinant human growth hormone and Gitelman's syndrome. Am J Kidney Dis 1999, 33:778-781.

12. Bettinelli A, Rusconi R, Ciarmatori S, Righini V, Zammarchi E, Donati MA, Isimbaldi C, Bevilacqua M: Gitelman disease associated with growth hormone deficiency, disturbances in vasopressin secretion and empty sella: a new hereditary renal tubular-pituitary syndrome? Pediatr Res 1999, 46:232-238.

13. Slyper AH: Growth, growth hormone testing and response to growth hormone treatment in Gitelman syndrome. J Pediatr Endocrinol Metab 2007, 20:257-259.

14. Itagaki Y, Tagawa T, Fujii F, Tanabe Y, Sumi K, Nose O, Seino Y: Bartter's syndrome with impairment of growth hormone secretion [abstract]. Clin Pediatr Endocrinol 1995, 4:213.

15. Nariai A, Yokoya S, Tajima T: Final height in two growth hormonedeficient patients with Bartter's syndrome treated with growth hormone in combination with luteinizing hormone-releasing hormone analog [abstract]. Clin Pediatr Endocrinol 2003, 12:166.

16. Yokoyama T, Ohyanagi K: A child case of Bartter syndrome with chronic renal failure treated by recombinant human hormones [abstract]. Clin Pediatr Endocrinol 1992, 1:57.

17. Flyvbjerg A, Dørup I, Everts ME, Orskov H: Evidence that potassium deficiency induces growth retardation through reduced circulating levels of growth hormone and insulin-like growth factor I. Metabolism 1991, 40:769-775.

18. Bogdanović R, Draaken M, Toromanović A, Dordević M, Stajić N, Ludwig M: A novel CLCN5 mutation in a boy with Bartter-like syndrome and partial growth hormone deficiency. Pediatr Nephrol 2010, 25:2363-2368.

19. Mulatero P, Monticone S, Rainey WE, Veglio F, Williams TA: Role of KCNJ5 in familial and sporadic primary aldosteronism. Nat Rev Endocrinol 2013, 9:104-112.

doi:10.1186/1752-1947-7-283

Cite this article as: Adachi et al: Classic Bartter syndrome complicated with profound growth hormone deficiency: a case report. Journal of Medical Case Reports 2013 7:283.

\section{Submit your next manuscript to BioMed Central and take full advantage of:}

- Convenient online submission

- Thorough peer review

- No space constraints or color figure charges

- Immediate publication on acceptance

- Inclusion in PubMed, CAS, Scopus and Google Scholar

- Research which is freely available for redistribution 